\title{
The relationship between breast and bottle feeding and respiratory illness in the first year of life
}

\author{
C. J. WATKINS, S. R. LEEDER, AND R. T. CORKHILL \\ From the Department of Community Medicine, St. Thomas's Hospital Medical School, London
}

SUMMARY The relationship between breast or bottle feeding and the incidence of bronchitis and pneumonia in the first year of life was examined in a birth cohort of nearly 2000 children born in Harrow, England, in 1963-65. Fewer episodes of acute bronchitis and pneumonia were reported in children who were breast-fed than in children who were bottle-fed. Firstborn children were more likely to be breast-fed than subsequent children. Mothers who smoked were less likely to breast-feed their babies. Although birth order and parental smoking have been shown to be associated with bronchitis and pneumonia in the same cohort, the association between feeding pattern and respiratory illness history persisted when these and other important factors were taken into account.

This paper examines the association of breastfeeding with acute lower respiratory illness in infancy when several social and family factors known to be associated with lower respiratory illness in infancy have been taken into account.

\section{Method}

The design of this study, sampling techniques, and data collection have been described in detail before (Leeder et al., 1976). In brief, a cohort of children born in 1963-65 in Harrow, a residential suburb of north-west London, was followed for the first five years of life, together with other members of their families. A total of 2365 Harrow families were eligible and of these 2205 were available for investigation. Health visitors saw infant and mother at home within 14 days of birth. The mother was asked: 'Are you breast-feeding the baby?' and her response was classified into breast-feeding only, complementing breast-feeding with the bottle, or bottle-feeding only. In addition, questions were asked about the birthweight of the infant and health at birth. Social class was estimated from the father's occupation. Housing conditions were uniformly good throughout the sample and there was no evidence of overcrowding. It should be appreciated that this sample was homogeneous with respect to social class and that at the time of the study there were no significant air pollution gradients operating within the area in which the study was conducted. Information was also obtained about parental smoking habits and respiratory symptoms. At the end of the first year of life, similar procedures for the collection of data were followed. At this stage, information was obtained about the child's history of respiratory illness in the past 12 months. Parents were asked specifically: 'Has he/she had in the past 12 months bronchitis or pneumonia?'. Adequate agreement was found between the parents' accounts of these illnesses and a sample of general practitioners' medical records. Complete data for the initial visit and the first year follow-up visit were available for analysis from 2074 families.

\section{Results}

The incidence of bronchitis and pneumonia in the first year of life was significantly less common in infants who were breast-fed than in those who were bottle-fed only $\left(\chi_{2}^{2}=20.35 ; P<0.001\right.$; Table 1$)$. In

Table 1 Annual incidence per 100 infants of bronchitis or pneumonia in the first year of life by feeding pattern and sex of infant $\dagger$

\begin{tabular}{llll}
\hline Feeding pattern & Boys & Girls & Total \\
\hline Breast-feeding only & $9 \cdot 5$ & $6 \cdot 7$ & $\mathbf{8 \cdot 1}$ \\
& $(494)$ & $(464)$ & $(958)$ \\
Breast-feeding plus complement & 12.9 & $12 \cdot 6$ & $12 \cdot 8$ \\
& $(147)$ & $(127)$ & $(274)$ \\
Bottle-feeding only & 16.8 & $12 \cdot 5$ & $14 \cdot 8$ \\
& $(458)$ & $(384)$ & $(842)$ \\
Total & 13.0 & $9 \cdot 7$ & $11 \cdot 5$ \\
& $(1099)$ & $(975)$ & $(2074)$ \\
\hline
\end{tabular}

† Numbers at risk in brackets. 
Table 2 Percentage of infants breast or bottle fed by age of mother, and ratio of children with bronchitis or pneumonia to number at risk (in brackets)

\begin{tabular}{|c|c|c|c|c|c|}
\hline \multirow[b]{2}{*}{ Feeding pattern } & \multicolumn{4}{|c|}{ Mother's age (years) } & \multirow[b]{2}{*}{ Total } \\
\hline & $<25$ & $25-29$ & $30-34$ & $35+$ & \\
\hline Breast-feeding only & $\begin{array}{c}50 \cdot 3 \\
(24 / 302)\end{array}$ & $\begin{array}{c}46 \cdot 1 \\
(28 / 379)\end{array}$ & $\begin{array}{c}42.9 \\
(20 / 187)\end{array}$ & $\begin{array}{r}41 \cdot 7 \\
(6 / 90)\end{array}$ & $\begin{array}{c}46 \cdot 2 \\
(78 / 958)\end{array}$ \\
\hline Breast-feeding plus complement & $\begin{array}{l}11 \cdot 0 \\
(9 / 66)\end{array}$ & $\begin{array}{l}12 \cdot 6 \\
(12 / 104)\end{array}$ & $\begin{array}{l}16.0 \\
(10 / 70)\end{array}$ & $\begin{array}{r}15 \cdot 7 \\
(4 / 34)\end{array}$ & $\begin{array}{c}13 \cdot 2 \\
(35 / 274)\end{array}$ \\
\hline Bottle-feeding only & $\begin{array}{c}38 \cdot 7 \\
(41 / 232)\end{array}$ & $\begin{array}{c}41 \cdot 2 \\
(49 / 339)\end{array}$ & $\begin{array}{c}41 \cdot 0 \\
(26 / 179)\end{array}$ & $\begin{array}{r}42.6 \\
(9 / 92)\end{array}$ & $\begin{array}{c}40.6 \\
(125 / 842)\end{array}$ \\
\hline Total & $\begin{array}{l}100 \cdot 0 \\
(74 / 600)\end{array}$ & $\begin{array}{l}100 \cdot 0 \\
(89 / 822)\end{array}$ & $\begin{array}{l}100 \cdot 0 \\
(56 / 436)\end{array}$ & $\begin{array}{l}100 \cdot 0 \\
(19 / 216)\end{array}$ & $\begin{array}{l}100 \cdot 0 \\
(238 / 2074)\end{array}$ \\
\hline
\end{tabular}

Table 3 Percentages of infants breast or bottle fed by maternal smoking habits, and ratio of children with bronchitis and pneumonia to population at risk (in brackets)

\begin{tabular}{|c|c|c|c|c|}
\hline \multirow[b]{2}{*}{ Feeding pattern } & \multicolumn{3}{|c|}{ Maternal smoking habits } & \multirow[b]{2}{*}{ Total } \\
\hline & Non-smoker & Ex-smoker & Current smoker & \\
\hline Breast-feeding only & $\begin{array}{c}50 \cdot 8 \\
(36 / 540)\end{array}$ & $\begin{array}{c}50.5 \\
(11 / 155)\end{array}$ & $\begin{array}{l}37 \cdot 3 \\
(31 / 263)\end{array}$ & $\begin{array}{c}46 \cdot 2 \\
(78 / 958)\end{array}$ \\
\hline Breast-feeding plus complement & $\begin{array}{l}12 \cdot 3 \\
(16 / 131)\end{array}$ & $\begin{array}{c}14 \cdot 0 \\
(2 / 43)\end{array}$ & $\begin{array}{c}14 \cdot 2 \\
(17 / 100)\end{array}$ & $\begin{array}{c}13 \cdot 2 \\
(35 / 274)\end{array}$ \\
\hline Bottle-feeding only & $\begin{array}{c}36.9 \\
(49 / 392)\end{array}$ & $\begin{array}{c}35 \cdot 5 \\
(10 / 109)\end{array}$ & $\begin{array}{c}48 \cdot 4 \\
(66 / 341)\end{array}$ & $\begin{array}{c}40.6 \\
(125 / 842)\end{array}$ \\
\hline Total & $\begin{array}{l}100 \cdot 0 \\
(101 / 1063)\end{array}$ & $\begin{array}{l}100 \cdot 0 \\
(23 / 307)\end{array}$ & $\begin{array}{l}100 \cdot 0 \\
(114 / 704)\end{array}$ & $\begin{array}{l}100 \cdot 0 \\
(238 / 2074)\end{array}$ \\
\hline
\end{tabular}

boys, $9 \cdot 5 \%$ of those who were breast-fed suffered from bronchitis or pneumonia compared with $16 \cdot 8 \%$ of those who were bottle-fed only. In girls, the incidence ranged from $6.7 \%$ in those who were breast-fed to $12 \cdot 5 \%$ in those who were bottle-fed only. For boys who received bottle complement, the incidence of bronchitis and pneumonia was intermediate between that of those who were either wholly breast-fed or wholly bottle-fed, but this trend was not seen in girls.

The older his mother, the less likely was it for a child to be breast-fed $\left(\chi^{2}\right.$ for linear trend $=4.07$; $P<0.05$; Table 2). Significantly fewer mothers who smoked breast-fed their children (Table 3). Mothers who smoked at the end of the first year of their infants' lives were significantly less likely to have breast-fed than non-smokers $(P<0 \cdot 001)$. Mothers who breast-fed reported fewer respiratory symptoms themselves than did other mothers, $\left(\chi^{2}\right.$ for linear trend $=4.40 ; P<0.05$; Table 4). The larger the family the less likelihood there was of the child being breast-fed $\left(\chi_{t}^{2}=16.88 ; P<0.01\right.$; Table 5).

Table 4 Annual incidence of maternal cough/phlegm by choice of feeding $\dagger$

\begin{tabular}{lrl}
\hline Feeding pattern & Maternal cough/phlegm \\
\hline Breast-feeding only & $7 \cdot 6 \%$ & $(958)$ \\
Breast-feeding plus complement & $11 \cdot 4 \%$ & $(274)$ \\
Bottle-feeding only & $10 \cdot 5 \%$ & $(842)$ \\
Total & $9 \cdot 1 \%$ & $(2074)$ \\
\hline
\end{tabular}

tNumbers at risk in brackets.

Table 5 Percentages of infants breast or bottle fed by numbers of siblings in the family : ratio of children with bronchitis or pneumonia to population at risk (in brackets)

\begin{tabular}{|c|c|c|c|c|c|}
\hline \multirow[b]{2}{*}{ Fecding pattern } & \multicolumn{4}{|c|}{ No. of siblings } & \multirow[b]{2}{*}{ Total } \\
\hline & 0 & 1 & 2 & 3 or more & \\
\hline Breast-feeding only & $\begin{array}{l}50 \cdot 5 \\
(20 / 455)\end{array}$ & $\begin{array}{c}43 \cdot 3 \\
(31 / 299)\end{array}$ & $\begin{array}{c}41.9 \\
(12 / 125)\end{array}$ & $\begin{array}{c}42 \cdot 7 \\
(15 / 79)\end{array}$ & $\begin{array}{c}46 \cdot 2 \\
(78 / 958)\end{array}$ \\
\hline Breast-feeding plus complement & $\begin{array}{c}13 \cdot 8 \\
(10 / 124)\end{array}$ & $\begin{array}{c}13.0 \\
(12 / 90)\end{array}$ & $\begin{array}{c}12 \cdot 7 \\
(8 / 38)\end{array}$ & $\begin{array}{l}11 \cdot 9 \\
(5 / 22)\end{array}$ & $\begin{array}{c}13 \cdot 2 \\
(35 / 274)\end{array}$ \\
\hline Bottle-feeding only & $\begin{array}{c}35 \cdot 7 \\
(36 / 321)\end{array}$ & $\begin{array}{c}43.7 \\
(45 / 302)\end{array}$ & $\begin{array}{c}45 \cdot 3 \\
(24 / 135)\end{array}$ & $\begin{array}{c}45 \cdot 4 \\
(20 / 84)\end{array}$ & $\begin{array}{c}40 \cdot 6 \\
(125 / 842)\end{array}$ \\
\hline Total & $\begin{array}{l}100 \cdot 0 \\
(66 / 900)\end{array}$ & $\begin{array}{l}100 \cdot 0 \\
(88 / 691)\end{array}$ & $\begin{array}{l}100 \cdot 0 \\
(44 / 298)\end{array}$ & $\begin{array}{l}100 \cdot 0 \\
(40 / 185)\end{array}$ & $\begin{array}{l}100 \cdot 0 \\
(238 / 2074)\end{array}$ \\
\hline
\end{tabular}


Variations in the incidence of lower respiratory tract illness in these infants in the first year of life have been related in previous analyses to sex, family size, sibling's illness history, parental respiratory history, and parental smoking (Leeder et al., 1976). Factors such as the social class of the parents, birthweight, and air pollution measurements have not been shown to be significantly associated with respiratory illness in the first year of life.

To assess the influence of these factors, together with breast and bottle feeding, on the incidence of bronchitis and pneumonia in the study children, a general linear interactive model (Nelder and Wedderburn, 1972) was fitted to the data, with the incidence of bronchitis and pneumonia as the outcome variable. When included in this analysis, breast-feeding added to the explanatory power of the model and it contributed significantly to the model independently of the other factors. There was no significant interaction in the model so that the relationship of bronchitis to each factor mentioned held independently at whatever the level of the other factors.

The model provided evidence of the explanatory power of these several variables in the estimated incidence rate. For example, in the bottle-fed children, the estimated incidence ranged from $42 \%$ in boys with more than two siblings, whose parents both smoked and whose mothers reported cough and phlegm, to $4.9 \%$ in girls with no siblings, neither of whose parents smoked nor reported cough/phlegm. In the breast-fed children, the equivalent estimates of incidence were $30 \%$ to $2.9 \%$. Thus, in the former group, bottle-fed babies appeared to be $12 \%$ more at risk of bronchitis and pneumonia than breast-fed babies, for whom the equivalent figure was $2 \%$.

\section{Discussion}

Our results confirm the independent relationship between breast-feeding and diminished risk of lower respiratory illness in the first year of life. In previous studies (Grulee et al., 1934; Robinson, 1951; Hooper, 1965), the association of breast-feeding with reduced risk could have been due to factors associated with breast-feeding rather than breast-feeding itself. We were able to take into account some factors associated with both bronchitis and pneumonia and breast-feeding, such as family size, parental smoking, and respiratory symptoms reported by the mother. Each of these factors explains some of the effects which could at first be attributed to breast-feeding; nevertheless, breast-feeding on its own is associated with significant variations in the incidence of bronchitis and pneumonia in the first year of life. It thus represents a very simple strategy which can be adopted to attempt to help reduce the incidence of these illnesses during the first year of life.

We thank Professor Walter Holland and Professor J. R. T. Colley, who provided the data for this study and were also responsible for data collection. We also thank Mr. A. V. Swan, Miss Susan Chinn, Mr. Andy Thomson, Mr. Öner Hassan, Mrs. Angela Wainwright, Mrs. Susan Gobel, and Miss Eloide Almeida. This study was supported in part by the Department of Health and Social Security.

Reprints from Dr. C. J. Watkins, Department of Community Medicine, St. Thomas's Hospital Medical School, London SE1 7EH.

\section{References}

Grulee, C. G., Sanford, H. N., and Herron, P. H. (1934). Breast and artificial feeding, influence on morbidity and mortality of twenty thousand infants. Journal of the American Medical Association, 103, 735-739.

Hooper, P. D. (1965). Infant feeding and its relationship to weight gain and illness. Practitioner, 194, 391-395.

Leeder, S. R., Corkhill, R. T., Irwig, L. M., Holland, W. W., and Colley, J. R. T. (1976). Influence of family factors on the incidence of lower respiratory illness during the first year of life. British Journal of Preventive and Social Medicine, 30, 203-212.

Nelder, J. A., and Wedderburn, R. W. M. (1972). Generalised linear models. Journal of the Royal Statistical Soc.A., 135, 370-384.

Robinson, M. (1951). Infant morbidity and mortality. A study of 3266 infants. Lancet, 1, 788-794. 